\begin{tabular}{lcc}
\hline Volume 4 & No. 3 & Desember 2016 \\
\hline
\end{tabular}

\title{
Cost Of Treatment Tonsilektomi Di Instalasi Bedah Sentral Rsud Kajen Kabupaten Pekalongan Tahun 2015
}

\author{
Imam Prasetyo ${ }^{1}$, Sudiro ${ }^{2}$, Chriswardani $S^{2}$ \\ 1) Rumah SakitUmum Daerah Kajen Kab.Pekalongan, imambludkajen@gmail.com \\ ${ }^{2)}$ Fakultas Kesehatan Masyarakat, Universitas Diponegoro, Semarang
}

Title : Tonsillectomy Cost of Treatment in Surgery Department in Kajen Public Hospital at Pekalongan District in 2015

\section{Abstrak}

Tarif pelayanan RSUD Kajen yang dibebankan pada pasien umum saat ini dibuat berdasarkan perhitungan biaya operasional yang terjadi, seperti biaya jasa medis, bahan habis pakai, obat - obatan, kelas perawatan, dan sewa kamar operasi, tetapi belum menghitung seluruh komponen biaya yang terlibat untuk tindakan tonsilektomi. Pembuatan tarif belum memperhitungkan biaya - biaya yang tidak langsung. Perda Nomor 1 Tahun 2012, untuk tindakan tonsilektomi RSUD Kajen berdasarkan telusur di rawat inap biaya penanganan tonsilektomi adalah Rp 3.275.100,00 untuk kelas 3, sedangkan untuk klaim BPJS tindakan tonsilektomi kelas 3 di RS Regional 1 tipe C Rp 1.767.900,00; dalam hal ini masih ada selisih biaya antara besaran biaya yang seharusnya dikeluarkan untuk penanganan tonsilektomi dengan besarnya klaim dari BPJS. Seharusnya setiap pembiayaan perlu dihitung dengan baik sesuai dengan clinical pathway agar dapat ditetapkan unit costnya sehingga dapat menjadi efektif dan efisien agar tercipta pelayanan kesehatan yang bermutu. Tujuan penelitian ini adalah mengetahui besaran unit cost berbasis clinical pathway pada diagnosis tonsilektomi di RSUD Kajen.

Jenis penelitian ini adalah penelitian observasional analitik dengan melakukan studi kasus di RSUD Kajen. Perumusan clinical pathway dilakukan melalui rapat tim penyusun. Perhitungan unit cost dilakukan dengan metode Activity Based Costing (ABC), penetapan biaya lebih.

Hasil perumusan clinical pathway menunjukkan bahwa tahapan pathway diagnosis tonsilektomi adalah admision (pendaftaran), diagnostic (pemeriksaan), therapy (pengobatan)
\& follow up (tindak lanjut). Dari perhitungan dengan metode $\mathrm{ABC}$ diperoleh unit cost diagnosis tonsilektomi sebesar Rp. 2.717.662,00. Hasil perhitungan analisis pemulihan biaya (cost recovery rate) diketahui bahwa CRR pada pasien umum sebesar $121 \%$ sedangkan pasien BPJS sebesar $65 \%$ hal ini menunjukkan bahwa untuk setiap pasien umum RSUD Kajen mendapatkan surplus sebesar $21 \%$ sedangkan untuk pasien BPJS RSUD Kajen mendapatkan minus sebesar $35 \%$.

Rekomendasi manajerial yang dapat diberikan adalah: penyusunan clinical pathway kemudian implementasi konsep final clinical pathway tersebut sebagai quality control RUSD Kajen. Disarankan agar RSUD Kajen melakukan penelusuran biaya dan monitoring serta evaluasi kepatuhan clinical pathway.

Kata Kunci : Unit Cost, Cost of Treatment, Clinical Pathway, Tonsilektomi

Referensi : $10(1990-2015)$

\section{Abstract}

Kajen Public Hospital service tariffs which was charged by noninsurance patients based operational tariffs that happened, such as medical services cost, consumable materials, drugs, patient room, and surgery room rental but has not calculated all cost component that involved in tonsillectomy procedure. Tariffs arragement has not calculated the indirect cost. Perda Nomor 1 Tahun 2012 for tonsillectomy procedure in Kajen Public Hospital based on an observation in ambulatory room, the tonsillectomy procedure cost was 3.275.100,00 for class 3, while $B^{r^{r r}}$ claim for tonssilectomy procedure in class $\mathcal{j}$ type C first region hospital was $R p$ 1.767.900, v, in this case there was a gap between real cost which charged for tonsillectomy procedure with expense claim from BPJS. It was necessary to well calculated every financing based on clinical pathway in order to set up the effective and 
eficient unit cost then the health service quality could improved. The study purpose was to analyse the unit cost based on clinical pathway in tonsillectomy procedure at Kajen Public Hospital.

The observational analytic research was a case study in Kajen Public Hospital. Clinical pathway formulation was done by committee meeting team. Unit cost calculation was done Activity Based Costing (ABC) method.

Clinical pathway formulation result was known that diagnosis pathway step of tonsillectomy was admision, diagnostic, therapy, and follow up. The calculation by $A B C$ method was given that tonsillectomy unit cost was Rp. 2.717.662,00. Analysis of cost recovery rate was known that CRR in non insurance patients was $121 \%$ while BPJS insurance patient was $65 \%$. This result showed that every non insurance patients of Kajen Public Hospital would get a surplus for about 21\% while BPJS insurance patient would get a minus for about $35 \%$.

The management recommendation for this study was an arragement of clinical pathway then final clinical pathway implementation concent as a quality control of Kajen Public Hospital. It was suggested that Kajen Public Hospital need to do an observation, monitoring, and evaluation in clinical pathway obidience.

Keyword : Unit Cost, Cost of Treatment, Clinical Pathway, Tonsillectomy

Bibliography : $10(1990-2015)$

\section{Pendahuluan}

Rumah sakit merupakan suatu bentuk organisasi yang unik dan kompleks, dan mempunyai sifat serta ciri dan fungsi khusus karena di dalamnya terdapat berbagai macam profesi yang terlibat untuk menghasilkan produk jasa pelayanan medis maka dalam perkembangannya baik ilmu dan teknologi harus dapat melihat berbagai aspek yang dapat mempengaruhi organisasi dalam memberikan pelayanan kesehatan. ${ }^{1}$ Mutu pelayanan rumah sakit di Indonesia perlu terus ditingkatkan sehingga dapat sejajar dengan mutu layanan rumah sakit di negara negara maju lainnya. Peningkatan mutu pelayanan tersebut dilakukan dengan setiap 3 (tiga) tahun sekali rumah sakit wajib mengikuti akreditasi rumah sakit sesuai ketentuan Pasal 40 Undang-Undang Rumah Sakit Nomor 44 Tahun 2009. Salah satu penilaian Standar Akreditasi Versi 2012 dilakukan survei pada Kelompok Standar Berfokus Pada Pasien tentang Pelayanan Anestesi dan Bedah (PAB) di mana salah satu penilaiannya meliputi ketersediaan dan kepatuhan Standar Prosedur Operasioanal, misalnya informed consent dan clinical pathways. $^{2}$

Identifikasi aktivitas penanganan tonsilektomi bermanfaat untuk menentukan model dalam melakukan analisis terhadap biaya penanganan tonsilektomi. Hasil analisis biaya akan bisa menentukan besarnya biaya yang muncul selama proses penanganan tonsilektomi, sehingga Rumah Sakit akan dapat mengambil langkah lanjutan untuk mengantisipasi masalah pendanaan penanganan tonsilektomi tersebut. Analisis biaya dengan cara menelusuri aktivitas sebagai penyebab biaya inilah dalam akuntansi biaya dikenal sebagai analisis biaya dengan metode Activity Based Costing (ABC). ${ }^{3}$ Untuk dapat menentukan besar koefisien efektivitas dan efisiensi pelayanan diperlukan sebuah penghitungan secara matang terhadap unit cost berbasis Clinical Pathways dengan medote analisis biaya berdasarkan Activity Based Costing. ${ }^{4}$

Dari hasil studi pendahuluan di RSUD Kajen, jumlah layanan tindakan tonsilektomi tahun 2012 - 2015 menempati posisi 5 teratas. Berdasarkan data tahun 2012 - 2015 di RSUD Kajen, jumlah tindakan tonsilektomi tanpa membedakan jenis tonsilektomi mengalami peningkatan setiap tahunnya dan terdapat 100 tindakan pada tahun 2015.

Dari segi pembiayaan, masih ada selisih biaya antara besaran biaya yang seharusnya dikeluarkan untuk penanganan tonsilektomi dengan besarnya klaim dari BPJS. Berikutnya adalah dalam pelaksanaan operasi tonsilektomi seharusnya menggunakan Clinical Pathways karena kasus tonsilektomi sering ditemui, menempati posisi 5 teratas, dan biayanya tinggi. Empat operasi teratas sebelumnya di RSUD Kajen telah memiliki Clinical Pathways. Dimana Clinical Pathways merupakan suatu konsep perencanaan pelayanan terpadu yang merangkum setiap langkah yang diberikan kepada pasien berdasarkan standar pelayanan medis dan asuhan keperawatan yang berbasis bukti dengan hasil yang terukur dan dalam 
jangka waktu tertentu selama di rumah sakit. ${ }^{5}$ Untuk dapat menentukan besar koefisien efektivitas dan efisiensi pelayanan diperlukan sebuah penghitungan secara matang terhadap unit cost berbasis Clinical Pathways dengan medote analisis biaya berdasarkan Activity Based Costing. ${ }^{6}$

Dari uraian latar belakang di atas, maka perlu dilakukan perancangan serta uji coba penerapan dokumen Clinical Pathways dan analisis biaya dengan metode Ativity Based Costing apakah biaya yang dibebankan pada pasien tonsilektomi sudah dapat menutupi seluruh biaya dalam layanan tindakan bedah tersebut dan apakah biaya tersebut sudah efisien dan efektif dalam layanan tindakan tonsilektomi.

\section{Metode Penelitian}

Penelitian ini merupakan penelitian observasional analitik dengan pendekatan cross sectional melalui survey menggunakan kuesioner, wawancara, dan observasi untuk mengetahui alur pelayanan tindakan tonsilektomi, serta biaya yang dikeluarkan untuk tindakan tonsilektomi kepada 10 responden.

\section{Hasil}

Inpatient Clinical Pathway Diagnosisi Tonsilektomi Versi RSUD Kajen

Mekanisme Penyusunan

Penyusunan draft inpatient clinical pathway dilakukan dilakukan melalui teknik Rapat Focus Group Discusion yang dihadiri oleh 2 dokter spesialis THT, 1 Kabid Pelayanan Medis, serta seorang notulis. Rapat dilakukan sebanyak 3 kali pertemuan dengan durasi waktu setiap pertemuan berkisar antara $60-120$ menit. Tempat pertemuan adalah di Ruang Rapat dengan menggunakan media komputer dan LCD Projector. Setelah Tim Penyusun Clinical Pathway melakukan rapat sebanyak 3 kali, maka tersusunlah draft Inpatient Clinical Pathway diagnosa Tonsilektomi.

Hasil Pertemuan Tim Penyusun Clinical Pathway

Pertemuan pertama mencari contoh atau acuan dalam penyusunan clinical pathway yang diambil dari Perhimpunan Dokter Spesialis Telinga hidung Tenggorokan Bedah Kepala Leher Indonesia. Pertemuan kedua membahas tentang draft inpatient clinical pathway berdasarkan contoh clinical pathway yang telah dipilih pada pertemuan pertama. Pertemuan ketiga membahas tentang kombinasi dari hasil pertemuan pertama dan kedua sehinggal akan diperoleh draft inpatient clinical pathway Tonsilektomi berserta penatalaksanaan versi RSUD Kajen.

Unit Cost Berbasis Clinical Pathway Tindakan Tonsilektomi

Proses penghitungan biaya satuan tindakan tonsilektomi dengan menggunakan metode activity based costing dengan langkah-langkah sebagai berikut: ${ }^{7}$

1. Melakukan activity centers pada unit yang terkait, biaya, dan cost driver masingmasing kategori biaya.

2. Membebankan biaya langsung yang dikonsumsi pada tindakan tonsilektomi.

3. Menentukan besarnya biaya indirect resource overhead dan direct resource overhead yang dikonsumsi masing-masing aktivitas dengan menggunakan proporsi waktu pada layanan terkait yaitu Klinik THT, Instalasi Bedah Sentral, dan Bangsal Mawar.

4. Menentukan activity center terkait tindakan tonsilektomi yang terdapat pada clinical pathway dan membebankan biaya overhead ke dalam masing-masing activity centers dalam clinical pathway 
Tabel 1 Biaya langsung tindakatan Tonsilektomi RSUD Kajen tahun 2015

\begin{tabular}{|c|c|c|c|c|}
\hline Kategori Biaya & Satuan & $\begin{array}{l}\text { Jumlah } \\
\text { Satuan }\end{array}$ & $\begin{array}{l}\text { Biaya } \\
\text { Satuan }\end{array}$ & Jumlah \\
\hline \multicolumn{5}{|l|}{ Pelayanan Poli } \\
\hline Pendaftaran & Aktivitas & 1 & 12.500 & 12.500 \\
\hline Konsultasi spesialis THT & TIndakan & 1 & 27.500 & 27.500 \\
\hline \multicolumn{5}{|l|}{ Pelayanan IBS } \\
\hline Tindakan dokter spesialisTHT & Tindakan & 1 & 300.000 & 300.000 \\
\hline Tindakan dokter spesialis Anastesi & TIndakan & 1 & 120.000 & 120.000 \\
\hline Alat & Alat & 1 & 87.190 & 87.190 \\
\hline Sterilisasi alat & Alat & 1 & 108.000 & 108.000 \\
\hline Laundry & $\mathrm{Kg}$ & 6.3 & 5.000 & 31.500 \\
\hline \multicolumn{5}{|l|}{ Obat dan bahan habis pakai } \\
\hline Braunol Sol & $\mathrm{Cc}$ & 50 & 110 & 5.520 \\
\hline Kasa Lipat 5 X 7 X 16ply & Pcs & 24 & 673 & 16.160 \\
\hline Handscoend St 6,5 Gamex & Pcs & 1 & 14.880 & 14.880 \\
\hline Handscoend St 7,5 Gamex & Pcs & 2 & 14.880 & 29.760 \\
\hline Catgut Pln 1 Resorba & $\mathrm{M}$ & 2 & 13.960 & 27.920 \\
\hline Aquadest Opls 25cc & $\mathrm{Flb}$ & 2 & 2.200 & 4.400 \\
\hline Spuit Terumo 2,5 Cc & Pcs & 1 & 2.960 & 2.960 \\
\hline Spuit Terumo $5 \mathrm{Cc}$ & Pcs & 1 & 3.520 & 3.520 \\
\hline Ringer Lactate $500 \mathrm{ml}$ & $\mathrm{Flb}$ & 1 & 9.520 & 9.520 \\
\hline Ondansetron $4 \mathrm{mg} / 2 \mathrm{ml} \mathrm{Inj}$ & Ampul & 1 & 7.760 & 7.760 \\
\hline Ett Non Kingking 7 Rusch 0,3 & Pcs & 1 & 72.960 & 72.960 \\
\hline Fentanyl $0,05 \mathrm{mg} / \mathrm{Ml} / 2 \mathrm{ml}$ & Ampul & 1 & 32.400 & 32.400 \\
\hline Ketorolac 30mg Inj & Vial & 1 & 26.800 & 26.800 \\
\hline Recofol 20mg/Ml 0.65 & Vial & 1 & 63.680 & 63.680 \\
\hline Atracurium Hammeln $2,5 \mathrm{mg} / 5 \mathrm{ml}$ & Vial & 1 & 75.920 & 75.920 \\
\hline Tramadol Inj & Ampul & 1 & 6.480 & 6.480 \\
\hline Forane $250 \mathrm{Ml}$ & $\mathrm{Cc}$ & 1 & 144.000 & 144.000 \\
\hline N2o $25 \mathrm{Kg}$ & $\mathrm{Cc}$ & 200 & 97 & 19.360 \\
\hline O2 Kap 6 & $\mathrm{Cc}$ & 200 & 11 & 2.160 \\
\hline Cefotaxime $1 \mathrm{G}$ & Ampul & 4 & 7.700 & 30.800 \\
\hline Ketorolac 30mg Inj & Vial & 5 & 13.376 & 66.880 \\
\hline Aquadest Opls $25 \mathrm{cc} \# 2 \mathrm{Flb}$ & $\mathrm{Flb}$ & 2 & 2.200 & 4.400 \\
\hline Materai & Barang & 1 & 12.500 & 12.500 \\
\hline Visite dokter spesialis anastesi & Kunjungan & 2 & 35.000 & 70.000 \\
\hline Visite dokter spesialis THT & Kunjungan & 2 & 35.000 & 70.000 \\
\hline \multicolumn{5}{|l|}{ Pelayanan Bangsal Mawar } \\
\hline Gizi (makan dan snack) & makan & 2 & 25.200 & 50.400 \\
\hline Laundry & $\mathrm{Kg}$ & 2 & 5.000 & 10.000 \\
\hline Admisitrasi rawat inap & aktivitas & 1 & 58.500 & 58.500 \\
\hline \multicolumn{5}{|l|}{ Penunjang } \\
\hline Darah Rutin & tindakan & 1 & 44.000 & 44,000 \\
\hline Ppt & tindakan & 1 & 45.600 & 45.600 \\
\hline Aptt & tindakan & 1 & 45.600 & 45.600 \\
\hline Gula Darah Strip & tindakan & 1 & 14.400 & 14.400 \\
\hline Hbsag (Rapid) Tes & tindakan & 1 & 40.000 & 40.000 \\
\hline Thorax & tndakan & 1 & 64.000 & 64.000 \\
\hline \multicolumn{5}{|l|}{ Obat } \\
\hline Ringer Lactate $500 \mathrm{ml}$ & Flb & 3 & 9.493 & 28.480 \\
\hline Cefixime Tab 100mg & Tab & 10 & 2.880 & 28.800 \\
\hline Tramadol Cap 50mg & $\mathrm{Tab}$ & 10 & 336 & 3.360 \\
\hline Total & & & & 1.940 .650 \\
\hline
\end{tabular}


Tabel 2 Biaya indirect resource overhead tindakan Tonsilektomi Klinik THT sesuai dengan clinical pathway

\begin{tabular}{lccrr}
\hline \multicolumn{1}{c}{ Aktivitas Klinik THT } & $\begin{array}{c}\text { Jumlah } \\
\text { Transaksi }\end{array}$ & \multicolumn{2}{c}{$\begin{array}{c}\text { Cost } \\
\text { Driver }\end{array}$} & \multicolumn{2}{c}{$\begin{array}{c}\text { Biaya Indirect Resource } \\
\text { Overhead per Aktivitas }\end{array}$} \\
\hline & & & $\begin{array}{c}\text { Harga } \\
\text { Satuan }\end{array}$ & \multicolumn{1}{c}{$\begin{array}{c}\text { Jumlah } \\
\text { Biaya }\end{array}$} \\
\hline Penerimaan pasien & 1 & pasien & 478 & 478 \\
\hline Pemeriksaan tanda vital & 1 & Aktivitas & 796 & 796 \\
\hline $\begin{array}{l}\text { Anamnesis, pemeriksaan fisik, diagnosis, penjelasan } \\
\text { medis, isi form, instruksi dokter }\end{array}$ & 1 & Aktivitas & 4.775 & 4.775 \\
\hline Pemberian resep dokter & 1 & Aktivitas & 796 & 796 \\
\hline Pengisian administrasi pasien yang akan rawat inap & 1 & Aktivitas & 2.388 & 2.388 \\
\hline Melakukan konsulan ke bagian dokter spesialis lain & 1 & Aktivitas & 2.388 & 2.388 \\
\hline Mengantar pasien yang akan menjalani rawat inap & 1 & Aktivitas & 3.183 & 3.183 \\
\hline Total biaya overhead & & & & 14.803 \\
\hline
\end{tabular}

Tabel 3 Biaya direct resource overhead tindakan Tonsilektomi Klinik THT sesuai dengan clinical pathway

\begin{tabular}{|c|c|c|c|c|}
\hline \multirow{2}{*}{ Aktivitas Klinik THT } & \multirow{2}{*}{$\begin{array}{l}\text { Jumlah } \\
\text { Transaksi }\end{array}$} & \multirow{2}{*}{$\begin{array}{c}\text { Cost } \\
\text { Driver }\end{array}$} & \multicolumn{2}{|c|}{$\begin{array}{l}\text { Biaya Direct Resource } \\
\text { Overhead per Aktivitas }\end{array}$} \\
\hline & & & $\begin{array}{l}\text { Harga } \\
\text { Satuan }\end{array}$ & $\begin{array}{c}\text { Jumlah } \\
\text { Biaya }\end{array}$ \\
\hline Penerimaan pasien & 1 & pasien & 63 & 63 \\
\hline Pemeriksaan tanda vital & 1 & Aktivitas & 104 & 104 \\
\hline $\begin{array}{l}\text { Anamnesis, pemeriksaan fisik, diagnosis, penjelasan } \\
\text { medis, isi form, instruksi dokter }\end{array}$ & 1 & Aktivitas & 626 & 626 \\
\hline Pemberian resep dokter & 1 & Aktivitas & 104 & 104 \\
\hline Pengisian administrasi pasien yang akan rawat inap & 1 & Aktivitas & 313 & 313 \\
\hline Melakukan konsulan ke bagian dokter spesialis lain & 1 & Aktivitas & 313 & 313 \\
\hline Mengantar pasien yang akan menjalani rawat inap & 1 & Aktivitas & 417 & 417 \\
\hline Total biaya overhead & & & & 1.941 \\
\hline
\end{tabular}

Tabel 4 Biaya indirect resource overhead tindakan Tonsilektomi Bangsal Mawar sesuai dengan clinical pathway

\begin{tabular}{|c|c|c|c|c|}
\hline \multirow{2}{*}{ Aktivitas Bangsal Mawar } & \multirow{2}{*}{$\begin{array}{l}\text { Jumlah } \\
\text { Transaksi }\end{array}$} & \multirow{2}{*}{$\begin{array}{c}\text { Cost } \\
\text { Driver }\end{array}$} & \multicolumn{2}{|c|}{$\begin{array}{l}\text { Biaya Direct Resource } \\
\text { Overhead per Aktivitas }\end{array}$} \\
\hline & & & $\begin{array}{l}\text { Harga } \\
\text { Satuan }\end{array}$ & $\begin{array}{l}\text { Jumlah } \\
\text { Biaya }\end{array}$ \\
\hline Persiapan ruangan & 1 & Kegiatan & 4.853 & 4.853 \\
\hline Menerima pasien baru & 1 & Kegiatan & 1.618 & 1.618 \\
\hline Serah terima berkas & 1 & Kegiatan & 971 & 971 \\
\hline Orientasi ruangan & 1 & Kegiatan & 4.853 & 4.853 \\
\hline Pemasangan gelang identitas & 1 & Kegitatan & 1.618 & 1.618 \\
\hline \multicolumn{5}{|c|}{$\begin{array}{c}\text { Tabel } 4 \text { Biaya indirect resource overhead tindakan Tonsilektomi Bangsal Mawar sesuai } \\
\text { dengan clinical pathway (lanjutan) }\end{array}$} \\
\hline \multirow{2}{*}{ Aktivitas Bangsal Mawar } & \multirow{2}{*}{$\begin{array}{c}\text { Jumlah } \\
\text { Transaksi }\end{array}$} & \multirow{2}{*}{$\begin{array}{c}\text { Cost } \\
\text { Driver }\end{array}$} & \multicolumn{2}{|c|}{$\begin{array}{l}\text { Biaya Direct Resource } \\
\text { Overhead per Aktivitas }\end{array}$} \\
\hline & & & $\begin{array}{l}\text { Harga } \\
\text { Satuan }\end{array}$ & $\begin{array}{c}\text { Jumlah } \\
\text { Biaya }\end{array}$ \\
\hline Pemeriksaan tanda vital & 5 & Kegiatan & 1.618 & 8.088 \\
\hline Pengkajian riwayat alergi, nyeri, risiko jatuh & 5 & Kegiatan & 4.853 & 24.264 \\
\hline Pemasangan intra vena line & 1 & Kegiatan & 4.853 & 4.853 \\
\hline Mengisi rekam medis (asuhan keperawatan) & 5 & Kegiatan & 1.618 & 8.088 \\
\hline Persiapan pre operasi & 1 & Kegiatan & 6.470 & 6.470 \\
\hline Penyiapan dan pemberian obat & 3 & Kegiatan & 4.853 & 14.558 \\
\hline Observasi perdarahan & 3 & Kegitatan & 1.618 & 4.854 \\
\hline Merawat luka & 3 & Kegiatan & 4.853 & 14.559 \\
\hline Melakukan balance cairan & 4 & Kegiatan & 1.618 & 6.470 \\
\hline
\end{tabular}




\begin{tabular}{llllr}
\hline Pengkajian fungsi saluran cerna & 3 & Kegiatan & 1.618 & 4.853 \\
\hline Personal hygiene & 5 & Kegiatan & 6.470 & 32.352 \\
\hline Pengisian rekam medis & 5 & Kegiatan & 1.618 & 8.088 \\
\hline Melepas infus dan gelang identitas & 1 & Kegiatan & 1.618 & 1.618 \\
\hline Mengembalikan kelebihan obat ke farmasi & 1 & Kegitatan & 4.853 & 4.853 \\
\hline Kelengkapan pasien pulang & 1 & Kegiatan & 3.235 & 3.235 \\
\hline Memberikan surat pengantar penyelesaian administrasi & 1 & Kegiatan & 1.618 & 1.618 \\
\hline Mengantar pasien pulang & 1 & Kegiatan & 4.853 & 4.853 \\
\hline Total & & & & 167.583 \\
\hline
\end{tabular}

Tabel 5 Biaya direct resource overhead tindakan Tonsilektomi Bangsal Mawar sesuai dengan clinical pathway

\begin{tabular}{|c|c|c|c|c|}
\hline \multirow{2}{*}{ Aktivitas Bangsal Mawar } & \multirow{2}{*}{$\begin{array}{l}\text { Jumlah } \\
\text { Transaksi }\end{array}$} & \multirow{2}{*}{$\begin{array}{c}\text { Cost } \\
\text { Driver }\end{array}$} & \multicolumn{2}{|c|}{$\begin{array}{l}\text { Biaya Direct Resource } \\
\text { Overhead per Aktivitas }\end{array}$} \\
\hline & & & $\begin{array}{l}\text { Harga } \\
\text { Satuan }\end{array}$ & $\begin{array}{c}\text { Jumlah } \\
\text { Biaya }\end{array}$ \\
\hline Persiapan ruangan & 1 & Kegiatan & 1.890 & 1.890 \\
\hline Menerima pasien baru & 1 & Kegiatan & 630 & 630 \\
\hline Serah terima berkas & 1 & Kegiatan & 378 & 378 \\
\hline Orientasi ruangan & 1 & Kegiatan & 1.890 & 1.890 \\
\hline Pemasangan gelang identitas & 1 & Kegitatan & 630 & 630 \\
\hline Pemeriksaan tanda vital & 5 & Kegiatan & 630 & 3.149 \\
\hline Pengkajian riwayat alergi, nyeri, risiko jatuh & 5 & Kegiatan & 1.890 & 9.448 \\
\hline Pemasangan intra vena line & 1 & Kegiatan & 1.890 & 1.890 \\
\hline Mengisi rekam medis (asuhan keperawatan) & 5 & Kegiatan & 630 & 3.149 \\
\hline Persiapan pre operasi & 1 & Kegiatan & 2.519 & 2.519 \\
\hline Penyiapan dan pemberian obat & 3 & Kegiatan & 1.890 & 5.669 \\
\hline Observasi perdarahan & 3 & Kegitatan & 630 & 1.890 \\
\hline Merawat luka & 3 & Kegiatan & 1.890 & 5.669 \\
\hline Melakukan balance cairan & 4 & Kegiatan & 630 & 2.519 \\
\hline Pengkajian fungsi saluran cerna & 3 & Kegiatan & 630 & 1.890 \\
\hline Personal hygiene & 5 & Kegiatan & 2.519 & 12.597 \\
\hline Pengisian rekam medis & 5 & Kegiatan & 630 & 3.149 \\
\hline Melepas infus dan gelang identitas & 1 & Kegiatan & 630 & 630 \\
\hline Mengembalikan kelebihan obat ke farmasi & 1 & Kegitatan & 1.890 & 1.890 \\
\hline Kelengkapan pasien pulang & 1 & Kegiatan & 1.260 & 1.260 \\
\hline $\begin{array}{llll}\begin{array}{l}\text { Memberikan } \\
\text { administrasi }\end{array} & \text { surat pengantar penyelesaian } \\
\end{array}$ & 1 & Kegiatan & 630 & 630 \\
\hline Mengantar pasien pulang & 1 & Kegiatan & 1.890 & 1.890 \\
\hline
\end{tabular}

Tabel 6 Biaya indirect resource overhead Tonsilektomi IBS sesuai dengan clinical pathways

\begin{tabular}{ccccc} 
& & & \multicolumn{2}{c}{ Biaya Indirect Resource } \\
\cline { 3 - 5 } Aktivitas Instalasi Bedah Sentral & Jumlah & Cost & \multicolumn{2}{c}{ Overhead per Aktivitas } \\
\cline { 4 - 6 } & Transaksi & Driver & Harga & Jumlah \\
& & & Satuan & Biaya
\end{tabular}

\begin{tabular}{lllrr}
\hline Identifikasi pasien & 1 & Kegiatan & 3.331 & \multicolumn{1}{c}{3.331} \\
\hline Serah terima pasien dan berkas RM & 1 & Kegiatan & 3.331 & 3.331 \\
\hline Cek persiapan alat dan bahan tindakan operasi & 1 & Kegiatan & 3.331 & 3.331 \\
\hline Cek list pre operasi & 1 & Kegiatan & 1.998 & 1.998 \\
\hline Cek persiapan alat dan bahan anastesi & 1 & Kegiatan & 9.992 & 9.992 \\
\hline Melakukan time in, durante, time out & 1 & Kegiatan & 9.992 & 9.992 \\
\hline Melaksanakan pembiusan oleh dokter spesialis & 1 & Kegiatan & 9.992 & 9.992 \\
\hline Melaksanakan operasi & 1 & Kegiatan & 19.983 & 19.983 \\
\hline Menulis laporan operasi & 1 & Kegiatan & 3.331 & 3.331 \\
\hline Menulis instruksi post operasi & 1 & Kegiatan & 3.331 & 3.331 \\
\hline Pemantauan pasien setelah operasi & 1 & Kegiatan & 19.983 & 19.983 \\
\hline Keputusan keluar dari recovery room setelah & 1 & Kegiatan & 3.331 & 3.331 \\
\hline
\end{tabular}




\begin{tabular}{lllllr}
\hline dokter spesialis anastesi & & & & & \\
\hline $\begin{array}{l}\text { Melakukan pemanggilan ke ruangan } \\
\text { menjemput pasien }\end{array}$ & untuk & 1 & Kegiatan & 1.332 & 1.332 \\
\hline Serah terima pasien dan berkas RM & & 1 & Kegiatan & 3.331 & 3.331 \\
\hline Total & & & & 96.586 \\
\hline
\end{tabular}

Tabel 7 Biaya direct resource overhead Tonsilektomi IBS sesuai dengan clinical pathway

\begin{tabular}{|c|c|c|c|c|}
\hline \multirow{2}{*}{ Aktivitas Instalasi Bedah Sentral } & \multirow{2}{*}{$\begin{array}{l}\text { Jumlah } \\
\text { Transaksi }\end{array}$} & \multirow{2}{*}{$\begin{array}{c}\text { Cost } \\
\text { Driver }\end{array}$} & \multicolumn{2}{|c|}{$\begin{array}{l}\text { Biaya Direct Resource } \\
\text { Overhead per Aktivitas }\end{array}$} \\
\hline & & & $\begin{array}{l}\text { Harga } \\
\text { Satuan }\end{array}$ & $\begin{array}{c}\text { Jumlah } \\
\text { Biaya }\end{array}$ \\
\hline Identifikasi pasien & 1 & Kegiatan & 6.334 & 6.334 \\
\hline Serah terima pasien dan berkas RM & 1 & Kegiatan & 6.334 & 6.334 \\
\hline Cek persiapan alat dan bahan tindakan operasi & 1 & Kegiatan & 6.334 & 6.334 \\
\hline Cek list pre operasi & 1 & Kegiatan & 3.800 & 3.800 \\
\hline Cek persiapan alat dan bahan anastes & 1 & Kegiatan & 19.002 & 19.002 \\
\hline Melakukan time in, durante, time out & 1 & Kegiatan & 19.002 & 19.002 \\
\hline 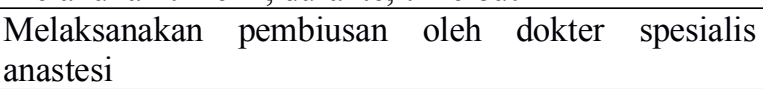 & 1 & Kegiatan & 19.002 & 19.002 \\
\hline Melaksanakan operasi & 1 & Kegiatan & 38.004 & 38.004 \\
\hline Menulis laporan operasi & 1 & Kegiatan & 6.334 & 6.334 \\
\hline Menulis instruksi post operasi & 1 & Kegiatan & 6.334 & 6.334 \\
\hline Pemantauan pasien setelah operasi & 1 & Kegiatan & 38.004 & 38.004 \\
\hline $\begin{array}{l}\text { Keputusan keluar dari recovery room oleh dokter } \\
\text { spesialis anestesi }\end{array}$ & 1 & Kegiatan & 6.334 & 6.334 \\
\hline $\begin{array}{l}\text { Melakukan pemanggilan } \\
\text { menjemput pasien }\end{array}$ & 1 & Kegiatan & 2.534 & 2.534 \\
\hline Serah terima pasien dan berkas RM & 1 & Kegiatan & 6.334 & 6.334 \\
\hline Total & & & & 183.685 \\
\hline
\end{tabular}

5. Menjumlahkan biaya langsung dan overhead yang terdapat dalam clinical pathway

Tabel 8 Unit cost Tonsilektomi

\begin{tabular}{lrr}
\hline \multicolumn{1}{c}{ Struktur biaya } & \multicolumn{2}{c}{ Biaya } \\
\hline \multicolumn{1}{c}{ Biaya langsung tonsilektomi } & 1.940 .650 \\
\hline \multicolumn{1}{c}{ Biaya overhead } & Indirect resource overhead & Direct resource overhead \\
\hline Klinik THT & 14.803 & 1.941 \\
\hline Bangsal Mawar & 167.683 & 65.254 \\
\hline Instalasi Bedah Sentral & 96.586 & 183.685 \\
\hline Total & & 2.470 .602 \\
\hline
\end{tabular}

\section{Pembahasan}

Beban Biaya dalam Perhitungan Unit Cost Tindakan Tonsilektomi

Dari perhitungan di atas didapatkan unit cost tindakan tonsilektomi dengan metode ABC sebesar Rp 2.470.602,00. Unit cost merupakan gambaran biaya yang harus disediakan oleh sebuah instansi dalam memberikan tindakan kesehatan pada masyarakat. Metode ABC didasarkan pada aktivitas yang menkonsumsi biaya di mana unit cost yang dihasilkan mampu memberi informasi biaya dan mampu memberikan upaya efisiensi aktivitas yang dianggap sebagai pemborosan. Metode $\mathrm{ABC}$ adalah metode yang memfokuskan pada aktivitas yang diyakini sebagai penyebab timbulnya biaya. $^{8}$

Beban biaya unit cost tindakan tonsilektomi terdiri dari:

Beban biaya langsung dalam perhitungan unit cost tindakan tonsilektomi

Beban biaya langsung dalam tindakan tonsilektomi sebesar $\mathrm{Rp}$ 1.940.650,00 atau sebesar $78.55 \%$ dari total beban biaya tonsilektomi. Tingginya beban biaya langsung pada tindakan tonsilektomi dikarenakan biaya obat dan barang habis pakai sebesar Rp $807.200,00$ (41\% dari total biaya langsung), biaya jasa medis sebesar Rp 907.690,00 (46\% dari total biaya langsung), dan beberapa tindakan prosedur rutin pre operasi, seperti 
pemeriksaan darah rutin, Ppt, Aptt, Hbsag, dan thorax sebesar Rp 253.600,00 (13\% dari total biaya langsung).

Biaya obat dan bahan medis habis pakai adalah beban biaya yang paling besar dalam keseluruhan tindakan tonsilektomi, namun bila ditelusur penggunaan obat dan bahan habis pakai sudah sesuai dengan formularium BPJS, yaitu menggunakan obat generik. Dalam hal ini tidak dapat dilakukan efisiensi biaya karena pemberian obat harus tepat dosis, tepat waktu, dan tepat jumlah. Kepatuhan dokter dalam memberikan obat sesuai dengan formularioum BPJS sangat berpengaruh terhadap mutu tindakan dan efisiensi biaya di rumah sakit. ${ }^{9}$

Selain obat dan barang habis pakai, jasa medis dokter spesialis THT dan dokter spesialis anastesi juga mengkonsumsi beban biaya yang cukup besar, yaitu jasa medis konsultasi di Klinik THT, visite pre operasi, visite post operasi, prosedur operasi tonsilektomi, dan anastesi di IBS. Rumah sakit hanya memberikan jasa dokter untuk tindakan tonsilektomi sebesar $50 \%$ dari jasa medis pasien umum lainnya sehingga sudah tidak dapat dilakukan efisiensi dalam hal besarnya jasa medis.

Beban biaya overhead dalam perhitungan unit cost tindakan tonsilektomi

Beban biaya overhead pada tindakan tonsilektomi sebesar $\mathrm{Rp} 529.952,00$ atau sebesar $21.45 \%$ dari total beban biaya tonsilektomi. Beban biaya tersebut terbagai dalam biaya overhead tonsilektomi Klinik THT sebesar $\mathrm{Rp} 16.744,00$ atau sebesar $0.68 \%$, Bangsal Mawar sebesar Rp 232.937,00 atau sebesar 9.43\%, dan IBS sebesar 280.271,00 dari total biaya tonsilektomi.

Biaya overhead pada masing-masing unit terbagi menjadi indirect dan direct resource overhead. Pada Kinik THT biaya indirect resource overhead sebesar $\mathrm{Rp}$ 14.803,00 lebih besar dibandingkan dengan biaya direct resource overhead, yaitu sebesar Rp 1.941,00. Pada Bangsal Mawar biaya indirect resource overhead yaitu sebesar $\mathrm{Rp}$ 167.683,00, lebih besar dibandingkan dengan biaya direct resource overhead sebesar $\mathrm{Rp}$ 65.254,00. Pada unit IBS biaya indirect resource overhead sebesar Rp 96.586,00 lebih kecil dibandingkan dengan direct resource overhead yaitu sebesar RP 183.685,00. Kecilnya biaya overhead dibandingkan dengan biaya langsung pada tindakan tonsilektomi dikarenakan konsumsi biaya depresiasi alat medis, non medis, dan gedung dikarenakan banyaknya tindakan dan jumlah pasien di rumah sakit.

Biaya overhead tonsilektomi paling besar dikonsumsi oleh biaya indirect resource overhead yang merupakan pembebanan biaya unit non fungsional. Lebih besarnya biaya pada indirect resoure overhead dibandingkan dengan direct resource overhead mencerminkan besarnya biaya unit non fungsional. Biaya indirect resource overhead non fungsional yaitu direksi, diklat, penunjang, pengadaan, satpam, dll. Banyaknya biaya yang dikonsumsi diakibatkan oleh banyaknya pegawai non fungsional yang berada di RSUD Kajen yaitu sebesar 107 dari 223 total pegawai sebesar $48 \%$ dari total pegawai.

Biaya yang dikonsumsi oleh direct resource overhead sebagian besar mencerminkan biaya pegawai yang langsung bersentuhan dengan pasien sebagai perawat. Dalam perhitungan unit cost ini biaya direct resource overhead lebih kecil dibandingkan indirect resource overhead di Klinik THT dan Bangsal Mawar.

Tarif tindakan tonsilektomi melalui perhitungan activity based costing, real payment, dan tarif INA CBG Tonsilektomi

Hasil perhitungan unit cost tindakan tonsilektomi dengan menggunakan metode activity based costing adalah $\mathrm{Rp} 2.464 .022,00$ dan dari perhitungan tarif (unit cost + margin) menggunakan kebijakan manajemen dengan laba sebesar lebih 10\% diperoleh kisaran tarif Rp 2.717.662,00. Penghitungan unit cost tonsilektomi dengan metode $\mathrm{ABC}$ yaitu sebesar Rp 2.717.662,00 dengan biaya langsung sebesar $\mathrm{Rp} 1.940 .650,00$ dan biaya overhead sebesar Rp 529.952,00. Sedangkan klaim tarif BPJS kelas III RS Tipe C sebesar Rp 1.767.900,00, yang berarti hanya mampu membiayai sebagain beban biaya operasional (biaya langsung) yang berarti pula bahwa besarnya tarif INA CBG tidak dapat digunakan untuk investasi rumah sakit. Dalam penghitungan tarif tidak semua pencetus biaya 
menggunakan margin $10 \%$, jenis pencetus biaya itu adalah materai dan pendaftaran. Materai dan pendaftaran tidak menghitung margin sama sekali.

Berdasarkan hasil perhitungan dan analisis di atas selanjutnya dilakukan analisis perbandingan antara unit cost dan patient real payment untuk dapat menentukan tingkat pemulihan biaya (CRR). Tingkat pemulihan biaya tersebut nantinya akan terbagi untuk pasien umum dan pasien BPJS, yaitu sebagai berikut:

CRR pasien umum

Rumus menghitung CRR pada pasien umum adalah sebagai berikut:

$$
\begin{aligned}
\text { CRR Pasien Umum } & =\frac{\text { Patient Real Cost }}{\text { Unit Cost }} \times 100 \% \\
\text { CRR Pasien Umum } & =\frac{\operatorname{Rp} 3.275 .100}{R p 2.717 .662} \times 100 \%
\end{aligned}
$$

CRR Pasien Umum $=121 \%$

Dari data di atas diketahui bahwa tingkat pemulihan biaya untuk pasien umum adalah sebesar $121 \%$. Hal ini menunjukkan bahwa rata-rata surplus yang diperoleh untuk setiap pasien umum adalah $21 \%$ dari nilai unit cost.

\section{CRR pasien BPJS}

Rumus menghitung CRR pada pasien BPJS adalah sebagai berikut:

$$
\begin{aligned}
\text { CRR Pasien BPJS } & =\frac{\text { Tarif BPJS }}{\text { Unit Cost }} \times 100 \% \\
\text { CRR Pasien BPJS } & =\frac{\operatorname{Rp} 1.767 .900}{R p 2.717 .662} \times 100 \% \\
\text { CRR Pasien BPJS } & =65 \%
\end{aligned}
$$

Dari data di atas diketahui bahwa tingkat pemulihan biaya untuk pasien BPJS adalah sebesar 65\%. Hal ini menunjukkan bahwa rata-rata minus yang diperoleh untuk setiap pasien BPJS adalah 35\% dari nilai unit cost.

Hal ini juga sesuai dengan penelitian sebelumnya yang dilakukan oleh Septianis (2009). Berdasarkan hasil penelitian mengenai kesesuaian biaya tindakan medik operatif terhadap tarif INA DRG pada program Jamkesmas di RS Mohamad Husein Palembang diperoleh kesimpulan bahwa biaya tindakan medik operatif yang dilakukan di RS Mohammad Husein Palembang 89.6\% tidak sesuai dan lebih besar dari tarif INA DRG. ${ }^{10}$

Rekomendasi Manajerial
Dari hasil penelitian di atas diketahui bahwa nilai CRR pada pasien BPJS hanya $65 \%$ dari unit cost yang menunjukkan bahwa tarif BPJS untuk kelas III belum mencukupi untuk menutup unit cost. Tahap pertama dalam dalam penelitian ini adalah menyusun inpatient clinical pathway tonsilektomi oleh tim penyusun berdasarkan evidence based clinical pathway Perhati. Setelah inpatient clinical pathway tonsilektomi telah selesai disusun diperlukan konfirmasi dari pakar atau konsultan di bidang ilmu yang sesuai dengan clinical pathway.

Tahap selanjutnya adalah pengimplementasian clinical pathway tonsilektomi. Dalam melakukan upaya tersebut diperlukan sebuah strategi atau tahapan rencana agar proses implementasi berjalan dengan lancar. Strategi rencana dalam implementasi clinical pathway yang dilakukan di RSUD kajen adalah sebagai berikut: melakukan sosialisasi, membuat surat keputusan direktur yang diharapkan dapat memaksa untuk melaksanakan dan mengimplementasikan clinical pathway yang telah disusun dan disepakati bersama, menerapkan reward and punishment (reward kepada dokter dan paramedis yang mengelola pasien diagnosis tonsilektomi sesuai dengan kriteria di dalam clinical pathway dengan diusulkan ke direktur masuk ke dalam Penilaian Kerja Profesional Dokter (Ongoing Profesional Performance Evaluation), di mana ketaatan hari rawat, pemeriksaan penunjang yang dilakukan, dan penggunaan obat sesuai formularium dimaksukkan dalam indeks peningkatan kinerja dokter dan punisment bagi dokter dan paramedis yang mengelola diagnosis tonsilektomi menyimpang jauh dari clinical pathway yang telah ditetapkan), dan setelah inpatient clinical pathway telah berhasil diimplementasikan, maka tahap terakhir adalah melakukan fungsi monitoring dan evaluasi.

\section{Kesimpulan}

Hasil perumusan clinical pathway menunjukkan bahwa tahapan pathway diagnosis tonsilektomi adalah admision (pendaftaran), diagnostic (pemeriksaan), therapy (pengobatan) \& follow up (tindak 
lanjut). Dari perhitungan dengan metode $\mathrm{ABC}$ diperoleh unit cost diagnosis tonsilektomi sebesar Rp. 2.717.662,00. Hasil perhitungan analisis pemulihan biaya (cost recovery rate) diketahui bahwa CRR pada pasien umum sebesar $121 \%$ sedangkan pasien BPJS sebesar $65 \%$ hal ini menunjukkan bahwa untuk setiap pasien umum RSUD Kajen mendapatkan surplus sebesar $21 \%$ sedangkan untuk pasien BPJS RSUD Kajen mendapatkan minus sebesar 35\%. Rekomendasi manajerial yang dapat diberikan adalah: penyusunan clinical pathway kemudian implementasi konsep final clinical pathway tersebut sebagai quality control RUSD Kajen. Disarankan agar RSUD Kajen melakukan penelusuran biaya dan monitoring serta evaluasi kepatuhan clinical pathway.

\section{Daftar Pustaka}

1. Ikhsan, Arfan, Dharmanegara, dan Ida Bagus Agung. Akuntansi dan Manajemen Keuangan Rumah Sakit, Edisi 1. Yogyakarta: Graha Ilmu; 2010.

2. UU RS NO 44 tahun 2009 tentang Rumah Sakit.

3. Baker, J.J. Activity Based Costing and Activity Based Management for Health Care. Gaithesburg, MD : Aspen Publisher, Inc; 1998.

4. Mahdi Javid, Mohammad Hadian. Application of The Activity Based Costing Method for Unit Cost Calculating in a
Hospital. Global Journal of Health Csience; 2015.

5. Firmanda. Dody. Penyusunan Clinical Pathway sebagai Dasar Penentuan Tarif Pelayanan Kesehatan Dalam Menyongsong Pelaksanaan SJSN Dan Akreditasi Rumah Sakit Versi Baru. Surabaya: FKM UNAIR; 2012.

6. Zohren Kazemi, Hassan Amirabadi. Activity Based Costing: A Practical Model for Cost Price Calculation in Hospital. Indian Journal of Science and Technology; 2015.

7. Cokins, G. Helbing, J. Stration, A. Sistem Activity Based Costing: Pedoman Dasar Bagi Manager. Jakarta: Pustaka Binaman Pressindo; 1990.

8. Mulyadi, Activity Based Cost Sy. Sistem Informasi Biaya u...... Pengurangan Biaya, UPPAMP YKPN, Yogyakarta, 2003.

9. Alatas, H. Peran Dokter Spesialis dalam Efisiensi Pelayanan Pasien Jamkesmas Rawat Inap di Rumah Sakit Umum Daerah Banyumas. Tesis. Purwokerto: Universitas Jendral Soedirman; 2002.

10. Septianis, Dwi. Alwi, Masnir, Misnaniarti. Perbandingan Biaya Pelayanan Tindakan Medik Operatif terhadap INA DRG pada Program Jamkesmas di Rumah Sakit Mohammad Husein Palembang; 2009. 